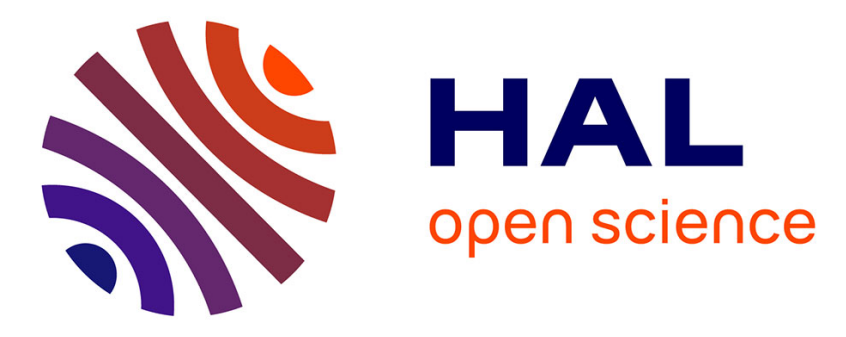

\title{
Temperature Coefficients of Quartz at Cryogenic Temperature
}

Jérémy Bon, Roger Bourquin, Philippe Abbé, Xavier Vacheret, Serge Galliou

\section{To cite this version:}

Jérémy Bon, Roger Bourquin, Philippe Abbé, Xavier Vacheret, Serge Galliou. Temperature Coefficients of Quartz at Cryogenic Temperature. International Frequency Control Symposium and European Frequency and Time Forum, Jul 2017, Besançon, France. hal-02472726

\section{HAL Id: hal-02472726 \\ https://hal.science/hal-02472726}

Submitted on 10 Feb 2020

HAL is a multi-disciplinary open access archive for the deposit and dissemination of scientific research documents, whether they are published or not. The documents may come from teaching and research institutions in France or abroad, or from public or private research centers.
L'archive ouverte pluridisciplinaire HAL, est destinée au dépôt et à la diffusion de documents scientifiques de niveau recherche, publiés ou non, émanant des établissements d'enseignement et de recherche français ou étrangers, des laboratoires publics ou privés. 


\title{
Temperature Coefficients of Quartz at Cryogenic Temperature
}

\author{
Jérémy Bon, Roger Bourquin, Philippe Abbé, Xavier Vacheret, Serge Galliou \\ FEMTO-ST, Time and Frequency dept. \\ Univ. Bourgogne Franche-Comté, CNRS, ENSMM \\ Besançon, France \\ Jeremy.bon@femto-st.fr, serge.galliou@femto-st.fr
}

\begin{abstract}
The temperature coefficients of the elastic coefficients of quartz within $[4 \mathrm{~K}, 15 \mathrm{~K}]$, the operating range of conventional cryocoolers, are predicted from experimental data. The raw data consist of a set of frequency-temperature curves recorded from bulk acoustic wave resonators made in different plates cut according to various angles relative to the crystallographic axes. Raw data are then processed as described in the paper to provide the $1^{\text {st }}, 2^{\text {nd }}$, and $3^{\text {rd }}$ order temperature coefficients of the seven elastic coefficients of quartz crystal.
\end{abstract}

Keywords-quartz; elastic coefficients; temperature coefficients; liquid-helium temperature; low mechanical loss; high quality factor.

\section{INTRODUCTION}

Usually temperature sensitivity cannot be neglected when designing a quartz resonator-based device. Even at temperatures lower than $6 \mathrm{~K}$, where the material properties are less sensitive to temperature than at room temperature, the remaining sensitivity has to be considered. The resonant frequency of a quartz crystal resonator is not an exception to this rule: the remaining fractional frequency change versus temperature is typically a few $10^{-9} \mathrm{~K}^{-1}$ close to $4 \mathrm{~K}$ [1-2]. This is still too much to realize a stable frequency source even with a temperature control exhibiting a typical gain of 1000: definitely, such an application would need a temperature compensated cut. It should be reminded that quartz resonators look very attractive around $4 \mathrm{~K}$ because of their very high quality factor that can be greater than one billion [3]. Conversely, quartz resonators could also be used as temperature sensors provided they are made in an appropriate cut, i.e. a very temperature-sensitive one. In both cases, to design a frequency reference or a temperature sensor the knowledge of the temperature coefficients of the elastic constants of the material is mandatory, the resonance frequency depending on these elastic constants. A set of coefficient values already exists for the quartz crystal since 1975 [4] but it covers the very wide range $[4 \mathrm{~K}, 400 \mathrm{~K}]$, and consequently becomes irrelevant inside the shorter operating range of conventional cryorefrigerators. These are the main reasons why we carried out a campaign of measurements to determine the $1^{\text {st }}, 2^{\text {nd }}$ and $3^{\text {rd }}$ order temperature coefficients of the elastic constants of quartz within [4 K, $15 \mathrm{~K}]$.

This work is supported by Conseil Régional de Franche-Comté. J.B. is thankful to Ministère de l'Enseignement Supérieur et de la Recherche, for his grant.

\section{METHOD OF CALCULATION}

The thermal coefficients can be determine from various experimental principles. It can be from resonant ultrasound spectroscopy, phase velocity measurements by pulse echo overlap methods, laser ultrasonic techniques or combined resonance techniques. Nevertheless, their implementation at cryogenic temperatures arises technical difficulties. The selected alternative consists in probing the temperature sensitivity of resonance frequencies of dedicated quartz devices.

\section{A. Theoretical principle}

Basically, a flat plate exhibits bulk acoustic waves (BAW) resonance frequencies derived from $f_{n}=\frac{n}{2 h} \sqrt{\frac{C_{e}}{\rho}}$ where $n$ is the overtone order, $2 h$ the plate thickness, $\rho$ its density, and $C_{e}$ an elastic coefficient that looks like a combination of the material elastic constants $C_{i j k l}$ depending on the cut orientation with respect to the crystallographic axis in case of quartz because of its anisotropy. All these parameters are temperature dependent yielding to a temperature-dependent frequency. Usually, the frequency-temperature characteristic can be fitted effectively by a $3^{\text {rd }}$ order polynomial approximation, and this operation can be applied to each parameter. Once experimental frequencytemperature records processed this way, the three corresponding temperature coefficients of the elastic coefficient(s) can be extracted accordingly. The calculation is just somewhat complicated by the fact that there are seven coefficients $C_{i j k l}$ for the quartz crystal. A set of combinations should therefore be considered involving a set of resonator cuts to be tested.

\section{B. Relationships and assumptions}

Actually, the tested devices are not flat plates but planoconvex disks, a shape commonly used to trap efficiently the acoustic energy. This is one way to preserve the resonator against disturbances from its environment (i.e. parasitic stresses and then frequency changes), and consequently a kind of guarantee to qualify the material regardless of the device structure. However, the modelling is complicated and the resulting frequency is as follows, according to the StevensTiersten model [5], one of the most accurate theories: 


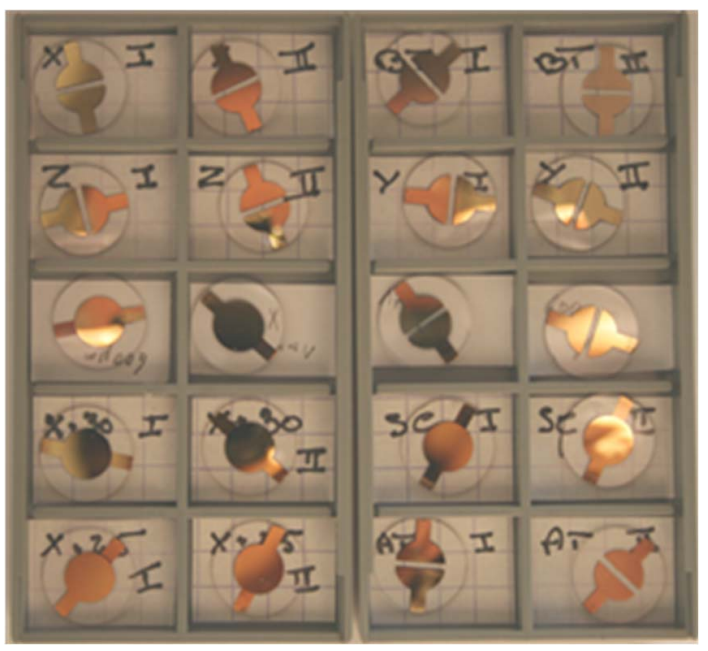

Fig. 1. Set of plano-convex resonators tested for determining the temperature coefficients of the elastic constants of quartz at $4 \mathrm{~K}$.

$$
f_{n m p}^{2}=f_{n}^{2}\left[1+\frac{1}{n \pi} \sqrt{\frac{2 h}{R_{0}}}\left(\sqrt{\frac{M_{n}}{C_{e}}}(2 m+1)+\sqrt{\frac{P_{n}}{C_{e}}}(2 p+1)\right)\right]
$$

Where $f_{n}$ are the eigenfrequencies of the corresponding infinite flat plate, $R_{0}$ the curvature radius of the convex face, $m$, $p$ the number of modal lines in the resonator plane, $M_{n}$ and $P_{n}$ the dispersion constants.

Nevertheless, several assumptions can be made by considering some orders of magnitude [6], and calculation proceeds according to the described process.

\section{EXPERIMENT}

\section{A. Experimental set-up}

Resonators have been tested in a conventional pulse tube cryorefrigerator SRP082B. The operating temperature is controlled at $\pm 3 \mathrm{mK}$ within $[4 \mathrm{~K}, 15 \mathrm{~K}$ ] by a Lakeshore 335 probing a cernox sensor and actuating a heater embedded inside the copper block where the resonator under test is set.

\section{B. Devices under test}

As mentioned above, a set of dedicated BAW energytrapped resonators with gold electrodes, as shown in Fig. 1, has been made and tested.

Table 1 shows, from left to right, from which cut and modes each experimental frequency-temperature characteristic is taken from, the corresponding frequency coefficients of the polynomial fit, and the targeted elastic coefficient(s).
TABLE I. TARGETED ELASTIC COEFFICIENTS

\begin{tabular}{|c|c|c|c|c|c|}
\hline \multirow[b]{2}{*}{ Cut } & \multicolumn{4}{|c|}{ From experimental data } & \multirow[b]{2}{*}{ Target } \\
\hline & Mode & $\begin{array}{c}T^{(I)} f \\
\operatorname{In} 10^{-7}\end{array}$ & $\begin{array}{c}T^{(2)} f \\
\operatorname{In} 10^{-8}\end{array}$ & $\begin{array}{c}T^{(3)} f \\
\operatorname{In} 10^{-9}\end{array}$ & \\
\hline AT & $\mathrm{C}_{300}, \mathrm{C}_{500}$ & 0.769 & 0.748 & 0.105 & $\mathrm{C}_{14}$ \\
\hline $\mathrm{SC}$ & $\mathrm{A}_{300}, \mathrm{~A}_{500}$ & -1.178 & -2.189 & -2.747 & $\mathrm{C}_{13}, \mathrm{C}_{33}$ \\
\hline $\mathrm{SC}$ & $\begin{array}{l}\mathrm{B}_{300}, \mathrm{~B}_{302} \\
\mathrm{~B}_{320}, \mathrm{~B}_{500}\end{array}$ & -0.879 & -1.672 & -1.832 & $\mathrm{C}_{13}, \mathrm{C}_{33}$ \\
\hline $\mathrm{X}$ & $\begin{array}{l}\mathrm{A}_{100}, \mathrm{~A}_{1300}, \\
\mathrm{~A}_{1500}\end{array}$ & -0.143 & -0.451 & -0.581 & $\mathrm{C}_{11},\left(\mathrm{C}_{12}^{\mathrm{a}}\right)$ \\
\hline $\mathrm{Y}$ & $\mathrm{C}_{300}, \mathrm{C}_{500}$ & 1.339 & 1.869 & 1.289 & $\mathrm{C}_{66}$ \\
\hline $\mathrm{Z}$ & $\mathrm{C}_{300}, \mathrm{C}_{500}$ & -1.465 & -2.662 & -3.571 & $\mathrm{C}_{44}$ \\
\hline
\end{tabular}

\section{RESULTS}

Table II shows the resulting $1^{\text {st }}, 2^{\text {nd }}$ and $3^{\text {rd }}$ order temperature coefficients of the Cij's, for quartz, with $T_{r e f}=8 \mathrm{~K}$.

TABLE II. RESULTING COEFFICIENTS

\begin{tabular}{|l|c|c|c|}
\hline \multicolumn{1}{|c|}{$\mathbf{C}_{\mathbf{i j}}$} & $\mathbf{T}^{(\mathbf{1})} \mathbf{C}_{\mathbf{i j k l}}$ in $\mathbf{1 0}^{-\mathbf{7}}$ & $\mathbf{T}^{(\mathbf{2})} \mathbf{C}_{\mathbf{i j k} \mathbf{l}}$ in $\mathbf{1 0}^{-\mathbf{8}}$ & $\mathbf{T}^{(\mathbf{3})} \mathbf{C}_{\mathbf{i j k l}}$ in $\mathbf{1 0}^{-\mathbf{9}}$ \\
\hline $\mathrm{C}_{11}$ & -0.235 & 1.28 & -3.25 \\
\hline $\mathrm{C}_{12}{ }^{\mathrm{b}}$ & -6.39 & -10.56 & -4.22 \\
\hline $\mathrm{C}_{13}$ & -7.18 & -7.42 & -0.877 \\
\hline $\mathrm{C}_{14}$ & -1.35 & -1.31 & -7.93 \\
\hline $\mathrm{C}_{33}$ & -4.62 & -5.65 & -7.62 \\
\hline $\mathrm{C}_{44}$ & -3.17 & -4.37 & -11.6 \\
\hline $\mathrm{C}_{66}$ & 3.08 & 5.92 & 0.486 \\
\hline
\end{tabular}

\section{CONCLUSION}

Resulting data will be used to identify temperature compensated cuts in the very useful range [ $4 \mathrm{~K}, 15 \mathrm{~K}$ ], where quartz resonators exhibit Q-factors of about one billion.

\section{REFERENCES}

[1] S. Galliou, J. Imbaud, R. Bourquin, N. Bazin, Ph. Abbé, "Outstanding quality factors of bulk acoustic wave resonators at cryogenic temperature", proc. 22nd EFTF, Toulouse, France, 5 pages (in DVD Toulouse Space Show), 22-25 April 2008.

[2] M. Goryachev, S. Galliou, J. Imbaud, R. Bourquin, Ph. Abbé, "Recent Investigations on BAW Resonators at Cryogenic Temperatures," IEEE IFCS-EFTF 2011, San Francisco, Ca, USA, May 2011.

[3] S. Galliou, M. Goryachev, R. Bourquin, Ph. Abbé, J. P. Aubry, and M. E. Tobar, "Extremely Low Loss Phonon-Trapping Cryogenic Acoustic Cavities for Future Physical Experiments," Nature: Scientific Reports, Sci. Rep. 3, 2132, 2013.

[4] A. G. Smagin, "Frequency-temperature characteristics of quartz crystal units of different cuts operating over a wide temperature range including helium temperatures" Proc. 49th IEEE IFCS, 31 May- 2 June 1995.

[5] D. S. Stevens, H. F. Tiersten, "An analysis of doubly rotated quartz resonators utilizing essential thickness modes with transverse variation," J. Acoust. Soc. Am. Vol.79, Nº6, pp. 1811-1826, June 1986.

[6] J. Bon, S. Galliou, R. Bourquin, "Temperature coefficients of crystallinequartz elastic constants over the cryogenic range [4 K, $15 \mathrm{~K}$ ]", Appl. Phys. Lett., 109, 231902 (2016). 